\title{
THE EMERGING DISCIPLINE OF COLLABORATIVE NETWORKS
}

\author{
Luis M. Camarinha-Matos ${ }^{1}$ and Hamideh Afsarmanesh ${ }^{2}$ \\ ${ }^{1}$ New University of Lisbon, PORTUGAL, cam@ uninova.pt \\ ${ }^{2}$ University of Amsterdam, THE NETHERLANDS, hamideh@ science.uva.nl
}

The process of creating a new scientific discipline for collaborative networks is addressed in this paper. Collaborative networks manifest in a large variety of forms, including virtual organizations, virtual enterprises, dynamic supply chains, professional virtual communities, collaborative virtual laboratories, etc. A large body of empiric knowledge related to collaborative networks is becoming available, but there is an urgent need to consolidate this knowledge and build the foundations for sustainable and solid research and development in this area. The establishment of a scientific discipline for collaborative networks is a strong instrument in achieving this purpose. Here, also the main characteristics of a "discipline" are analyzed in the context of collaborative networks, showing that the pre-conditions necessary for building this new discipline are available.

\section{INTRODUCTION}

A large variety of collaborative networks have emerged during the last years as a result of the challenges faced by both the business and scientific worlds. Advanced and highly integrated supply chains, virtual enterprises / virtual organizations, professional virtual communities, value constellations, and collaborative virtual laboratories, represent only the tip of a major trend in which enterprises and professionals seek complementarities and joint activities to allow them participate in competitive business opportunities, in new markets and / or reaching scientific excellence for innovative developments.

A large number of research projects are carried out worldwide and a growing number of practical cases on different forms of collaborative networks are being reported. This trend has so far led to an extensive amount of empirical base knowledge that now needs to be leveraged. In addition to the identification of many required components, tools, and the base infrastructure functionalities, awareness is being built and partially studied, even in the traditional collaborative organizations, regarding the fundamental configuration and operational rules, as well as the behavioral patterns that emerge. It is now urgent to consolidate and synthesize the existing knowledge, setting a sound foundation for the future research and 
development in this area. The establishment of a scientific discipline for collaborative networks is a strong instrument in achieving this purpose.

But what is a scientific discipline?

According to Liles et al. [1], a discipline has six basic characteristics (Fig.1).

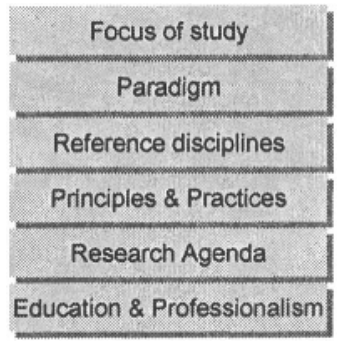

Figure 1 - Characteristics of a discipline [1]

Next sections will analyze each one of these characteristics in the context of collaborative networks $(\mathrm{CN})$, showing that the pre-conditions for the establishment of this new discipline already exist.

\section{FOCUS OF STUDY}

A discipline of collaborative networks shallfocus on the structure, behavior, and evolving dynamics of networks of autonomous entities that collaborate to better achieve common or compatible goals. This study shall devise principles and practices for the analysis, design, implementation, and operation of CNs.

During the last years various manifestations or variants of collaborative networks have emerged [3] such as, for example:

- Virtual enterprise (VE) - a temporary alliance of enterprises that come together to share skills or core competencies and resources in order to better respond to business opportunities, and whose cooperation is supported by computer networks.

- Virtual Organization (VO) - a concept similar to a virtual enterprise, comprising a set of (legally) independent organizations that share resources and skills to achieve its mission / goal, but that is not limited to an alliance of for profit enterprises. A virtual enterprise is therefore, a particular case of virtual organization.

- Dynamic Virtual Organization - typically refers to a VO that is established in a short time to respond to a competitive market opportunity, and has a short life cycle, dissolving when the short-term purpose of the VO is accomplished.

- Extended Enterprise - a concept typically applied to an organization in which a dominant enterprise "extends" its boundaries to all or some of its suppliers. An extended enterprise can be seen as a particular case of a virtual enterprise.

- VO Breeding environment (VBE) - represents an association (also known as 
cluster) or pool of organizations and their related supporting institutions that have both the potential and the will to cooperate with each other through the establishment of a "base" long-term cooperation agreement and interoperable infrastructure. When a business opportunity is identified by one member (acting as a broker), a subset of these organizations can be selected and thus forming a VE/VO.

- Professional virtual community (PVC) - represents the combination of the concepts of virtual community and professional community. Virtual communities are defined as social systems of networks of individuals, who use computer technologies to mediate their relationships. Professional communities provide environments for professionals to share the body of knowledge of their professions such as similar working cultures, problem perceptions, problem-solving techniques, professional values, and behavior.

- e-Science - is about global (i.e. networked) collaboration in key areas of science, and the next generation of ICT infrastructure that enables flexible, secure, coordinated resource-sharing among dynamic collections of individuals, institutions and resources.

- (Collaborative) Virtual laboratory (VL) - represents a heterogeneous and distributed problem solving environment that enables a group of researchers located in different geographically spread centers to work together, sharing resources (equipments, tools, data and information related to experiments, etc.). VL can be seen as part of e-Science.

- Agile shop floor - modeling shop floor resources as a collaborative network and applying multi-agent based coalitions is a promising approach to allow rapid changes in the shop-floor infrastructure and its control system [5].

\begin{tabular}{|c|c|c|c|c|}
\hline $\begin{array}{l}\text { Long term } \\
\text { association } \\
\text { Ready to } \\
\text { collaborate }\end{array}$ & $\begin{array}{l}\text { Virtual } \\
\text { Organization I } \\
\text { Virtual } \\
\text { enterprise } \\
\text { Temporary } \\
\text { network } \\
\text { Goal } \\
\text { oriented } \\
\text { consortium }\end{array}$ & $\begin{array}{l}\text { Professional } \\
\text { Virtual } \\
\text { Community }\end{array}$ & $\begin{array}{l}\text { E-Science I } \\
\text { Virtual Labs } \\
\text { Mix network } \\
\text { people- } \\
\text { organizations } \\
\text { Access to } \\
\text { remote } \\
\text { equipment }\end{array}$ & $\begin{array}{l}\text { Dynamic } \\
\text { cells of } \\
\text { manufacturing } \\
\text { resources }\end{array}$ \\
\hline \multicolumn{5}{|c|}{ Collaborative Networks } \\
\hline \multicolumn{5}{|c|}{$\begin{array}{l}\text { Networks of autonomous organizations, people, resources, or mixed } \\
\text { Common goals to be achieved by collaboration } \\
\text { Agreed principles of operation and interoperable infrastructures }\end{array}$} \\
\hline
\end{tabular}

Figure 2 - Examples of manifestations of collaborative networks

In addition to these more widely known forms, other types of collaborative networks are emerging, e.g. rescue teams, time bank, elderly care networks, gaming communities, virtual institutes. [4].

Some common "patterns" and common elements can be intuitively found in all these various manifestations, e.g. (i) all cases show networks of autonomous entities (organizations, people, resources, or mixed) located in different locations, (ii) they are driven by common goals / intentions to be achieved by collaboration, and (iii) 
they operate based on agreed principles and interoperable infrastructures to cope with their heterogeneity.

However one of the main weaknesses in the area is the lack of appropriate definitions and formal theories, consistent modeling paradigms and formal modeling tools. There is not yet even a common definition of the basic examples of collaborative networks, such as the virtual organization, professional virtual communities, breeding environments, virtual enterprise, or collaborative virtual laboratories. This situation constitutes a major obstacle for interaction among experts from multiple disciplines, involved in this area, and creates an obstacle for the recognition of collaborative networks as a new scientific paradigm.

Another question is which name should be given to this new scientific discipline? In the literature, a large variety of terms have been suggested to represent the various manifestations of collaborative networks. Some of these terms have a very short life, simply due to the "anxiety" observed in some research groups to always generate new names. Some other terms are better established that in fact address and distinguish different forms of this phenomenon. When establishing a discipline we should however aim at a name that can represent the widest set of manifestations, not being linked to any particular sub-group or application domain, and also being a term that intuitively gives a first idea of the main elements of the wide paradigm. Therefore, we suggest the term "collaborative networks" (CN) as a suitable name for this new discipline.

\section{A NEW PARADIGM}

CNs are complex systems, emerging in many forms in different application domains, and consist of many facets whose proper understanding requires the contribution from multiple disciplines. In fact the various manifestations of CNs have been studied by different branches of science, including the computer science, computer engineering, management, economy, sociology, industrial engineering, law, etc., to name a few. We are now in the stage that Kuhn [2] would call a preparadigmatic phase, in which the collaborative networks phenomenon is being described and interpreted in many different ways, depending on the background of the researcher.

The acceptance of a new paradigm is not a pacific process [2], as the established sciences and paradigms tend to resist the introduction of another new paradigm, and rather prefer to extend the existing sciences or paradigms and their associated rules to explain the new phenomena. This tension situation is further increased by the multi-disciplinaritiy of the phenomena, namely in the case where multiple traditional disciplines / branches of organized knowledge and professionals compete to claim and master the new area. This is the clear case we observe today for collaborative networks.

As a good example of this strained behavior, so far several of the established branches of science have tried to use / extend their definition and behavior of the single enterprise paradigm to explain the collaborative networks; e.g. the attempts in the direction of "enterprise engineering" and "enterprise architect", among others. Considering VE as just another form of an enterprise naturally leads to consider that 
extending the existing models of a single enterprise would be a promising approach. However, anomalies appear when the existing enterprise-centric models and their extensions fall short of capturing the key facets and specificities intrinsic in networked organizations, as well as when realizing that the base facilities of the applied discipline is not sufficient to properly represent and model all aspects of the behavior of collaborative networks. Instead of focusing on the internal specificities and tight interconnections among the internal components of an enterprise, the focus in collaborative networks must be directed to the external interactions among autonomous (and heterogeneous) entities (e.g. interoperability mechanisms and tools, etc.), the roles of those entities (e.g. coordinator, member, cluster-manager, broker, etc.), the main components that define the proper interaction among entities (e.g. common ontologies, contracts, DBP, distributed multi-tasking, collaborative language, etc.), the value systems that regulate the evolution of the collaborative association (e.g. collaborative performance records, etc.), and the emerging collective behavior (e.g. trust, teamwork, etc.), among others.

In the history of science, the recognition and acknowledgement of anomalies has resulted in "crises", that are the necessary preconditions for the emergence of novel theories and for a paradigm change or even the rise of a new discipline. Therefore CNs cannot be seen as proprietary to one of these single disciplines, rather representing a new emerging discipline of its own.

As in other past paradigm changes, considerable research efforts have been focused on identification of "anomaly" aspects for CNs, i.e. the identification of what is new in the collaborative networks in reference to the established body of knowledge, that has itself lead to the induction and progressive characterization of a new scientific paradigm. A new scientific discipline emerges once: (i) the new paradigm is adjusted to cover the various manifestations of the emerging collaborative forms, (ii) the consolidated set of basic knowledge is organized, and (iii) the various multi-disciplinary researchers involved in this work start to identify themselves as members of this new community, rather than doing research on collaborative networks while staying as members of their original communities and disciplines.

As it has happened many times in the past history of sciences [2], it is natural that at the beginning of this process various formulations / interpretations / theories compete (e.g. the various existing definitions of virtual organization in the literature). This process continues until a comprehensive definition becomes accepted by a large majority, namely when eventually the one that better explains the various manifestations of collaborative networks will be settled in this position.

\section{REFERENCE DISCIPLINES}

Disciplines, like the proposed one, are based upon other disciplines that can be called the reference disciplines or adjacent disciplines [1]. Developments in CNs have benefited from contributions of multiple disciplines, namely computer science, computer engineering, communications and networking, management, economy, social sciences, law and ethics, etc. Furthermore some, theories and paradigms defined elsewhere have been suggested by several research groups as promising 
tools to help define and characterize emerging collaborative organizational forms. Examples are [3]:

- Formal theories and modeling of dynamic networks - contributing to solve design problems (architecture, protocols, network creation), specify systems and verify specifications focused on correctness and completeness, testing and verification of implementations.

- Graph theory - contributing to represent networks of relationships (topology, routing, activity, flow), and perform computations on flows, optimization, etc.

- Formal engineering methods - contributing to the description of operational behavior of $\mathrm{CN}$, formulating operational plans that binding partners (consumers/suppliers) in $\mathrm{CN}$, formal verification (if the plans are indeed satisfied by the operational behavior), etc.

- Semiotics, normative models and multi-agents - potentially contributing to model the responsibility relationships and commitments, to prescribe norms, roles and legal support, and capture the system requirements.

- Network analysis and game theory - contributing to the selection of partners, sustaining cooperation and trust (non-cooperative game theory), distribution of responsibility and resources (cooperative game theory), coordination, efficiency, power relationships, and maintenance of ties and reputation (network exchange theory), etc.

- Temporal and modal logic - contributing to the modeling of the operational phase aspects; and to support synthesis of processes.

- Metaphors - contributing to the description for human communication (a possible help in expressing complex ill-defined concepts); to be used in early stages of analysis (conceptual design).

- Theories of complexity - contributing to the analysis of self-organizing behavior, learning how to manage chaotic dynamics, and provide insights on CN's behavior ("small-worlds").

- Dynamic ontologies - unlike static ontologies, dynamic ontologies contribute to the capture of the evolution of mutual understanding among members of the network.

More recently researchers have also started to look into the "soft computing" area in order to find suitable approaches for modeling aspects related to human behavior in collaborative organizations and to handle the issues of decision making and behavior management in the contexts of incomplete and imprecise knowledge.

These disciplines and theories need to be further investigated in order to determine what specific contributions they can bring in to the $\mathrm{CN}$ and their level of closeness and appropriateness.

\section{PRINCIPLES AND PRACTICES}

An ordered set of principles and practices form the foundation of a discipline [1]. In the case of Collaborative Networks and their manifestations, a large number of R\&D 
projects and practical implementations have been developed during last years. Particularly in Europe, more than 100 projects have been supported by the European Commission, in addition to various national initiatives. However, each one of these efforts has only addressed particular facets of the $\mathrm{CNs}$, leading to some fragmentation of research. Furthermore most of the early initiatives were of an adhoc nature, not relying on sound theories and principles.

In spite of this ad-hoc and fragmented research situation, a growing set of principles and practices has been collected in many projects and pilot applications. Fig. 3 illustrates some of the common practices applied to the $\mathrm{CN}$ development.

At present, the main phases of the life cycle of a $\mathrm{CN}$ are intuitively understood and the main required support functionalities are being identified. It is also nowadays a widely accepted principle that the effective establishment of dynamic VOs requires an underlying breeding environment (or cluster network). A variety of such breeding environments or clusters can already be identified for instance in Europe, Japan, Brazil, and Mexico.

\begin{tabular}{|c|c|}
\hline Focus area & Some "practices" (technologies \& standards) \\
\hline Coordination & $\begin{array}{l}\text { - Workflow (distributed), WfMC reference model } \\
\text { - Distributed business process modeling, PSL, ... } \\
\text { - WS-Coordination }\end{array}$ \\
\hline $\begin{array}{l}\text { Information } \\
\text { Management }\end{array}$ & $\begin{array}{l}\text { - Federated information management } \\
\text { (loosely / tightly coupled), (import/export schemas, } \\
\text { federated query processing) } \\
\text { - Visibility / access rights }\end{array}$ \\
\hline $\begin{array}{l}\text { Information } \\
\text { Exchange \& } \\
\text { Interoperability }\end{array}$ & $\begin{array}{l}\text { - EDIFACT, STEP, ... } \\
\text { - XML-based standards, ebXML, RosettaNet } \\
\text { - ODMG, webDAV, ... }\end{array}$ \\
\hline $\begin{array}{l}\text { Secure } \\
\text { Communications }\end{array}$ & $\begin{array}{l}\text { - Cryptography (symetric / asymetric), } \\
\text { authentication, digital signature, certificates } \\
\text { - VPN, Grid security framework } \\
\text { - SAML, XMLENC, XMLDSIG, XKMS, ... }\end{array}$ \\
\hline Contracts & $\begin{array}{l}\text { - Negotiation protocols, auctions } \\
\text { - Contract modeling }\end{array}$ \\
\hline $\begin{array}{l}\text { Horizontal } \\
\text { Infrastructure }\end{array}$ & $\begin{array}{l}\text { - Transaction-oriented } \\
\text { - Multi-agent based (stationary \& mobile agents) } \\
\text { - Web-services based (WSDL, UDDI, SOAP,...) }\end{array}$ \\
\hline $\begin{array}{l}\text { Resources } \\
\text { Management }\end{array}$ & $\begin{array}{l}\text { - GRID } \\
\text { - UPnP, WSDL, ... }\end{array}$ \\
\hline $\begin{array}{l}\text { Infrastructure } \\
\text { Development }\end{array}$ & $\begin{array}{l}\text { - J2EE, .NET } \\
\text { - CORBA } \\
\text { - FIPA } \\
\text { - Globus Toolkit, OGSA-DAI, DAIS, Spitfire }\end{array}$ \\
\hline
\end{tabular}

Figure 3 - Some principles and practices in $\mathrm{CN}$ 


\section{RESEARCH AGENDA}

A scientific discipline for Collaborative Networks is characterized by the existence of an active research agenda where many fundamental questions are being tackled and studied. In principle, the existence of an active research agenda is revealed if the following three main characteristics exist [1]:

1. It stands the test of time. CNs represent an active research area for more than 15 years. During this time a growing number of research projects have been launched world-wide and many pilot application cases are being developed in different regions for a variety of application domains. Definition of challenges and the research questions are becoming more precise and detailed, and their dimension more evident as our knowledge about the area accumulates. It is therefore becoming clear that this is not a temporaryfashion but rather a major area of research that continuously grows.

2. It is complex, and substantial enough to be subdivided into different research directions. CNs represent a vast area of research that requires a subdivision into a number of research areas in order to be studied and handled. This subdivision can be based for instance, on the type of manifestation (VE/VO, PVC, VL, etc), or on different technical perspectives (e.g. socioeconomic focus, management focus, ICT infrastructure focus, ICT support services focus, theoretical foundation focus).

3. Multiple fundamental questions/approaches are raised and formulated to guide the research in the area. A large and growing number of open issues and research challenges are being identified in the various manifestations of the $\mathrm{CNs}$ and their focus areas. These questions are illustrated by a number of research roadmaps related to collaborative networks, that are elaborated recently, namely in Europe [3].

An example of a comprehensive research agenda for CNs is given by the VOmap roadmap for advanced virtual organizations [6], [7]. VOmap aimed at identifying and characterizing the key research challenges needed to fulfill the vision, required constituency, and the implementation model for a comprehensive European initiative on dynamic collaborative virtual organizations (VO). The VOmap vision is that of an effective transformation of the landscape of European industry into a society of collaborative relationships. In order to be efficient and competitive in their operation, VOs of the future have to rely on solid bases and strong methodological approaches. This roadmap, which includes contributions from about 100 experts from industry and academy, identifies a large number of the main challenges for research and development in this area, and suggests a time frame for the proposed research actions, as shown in Fig. 4. 


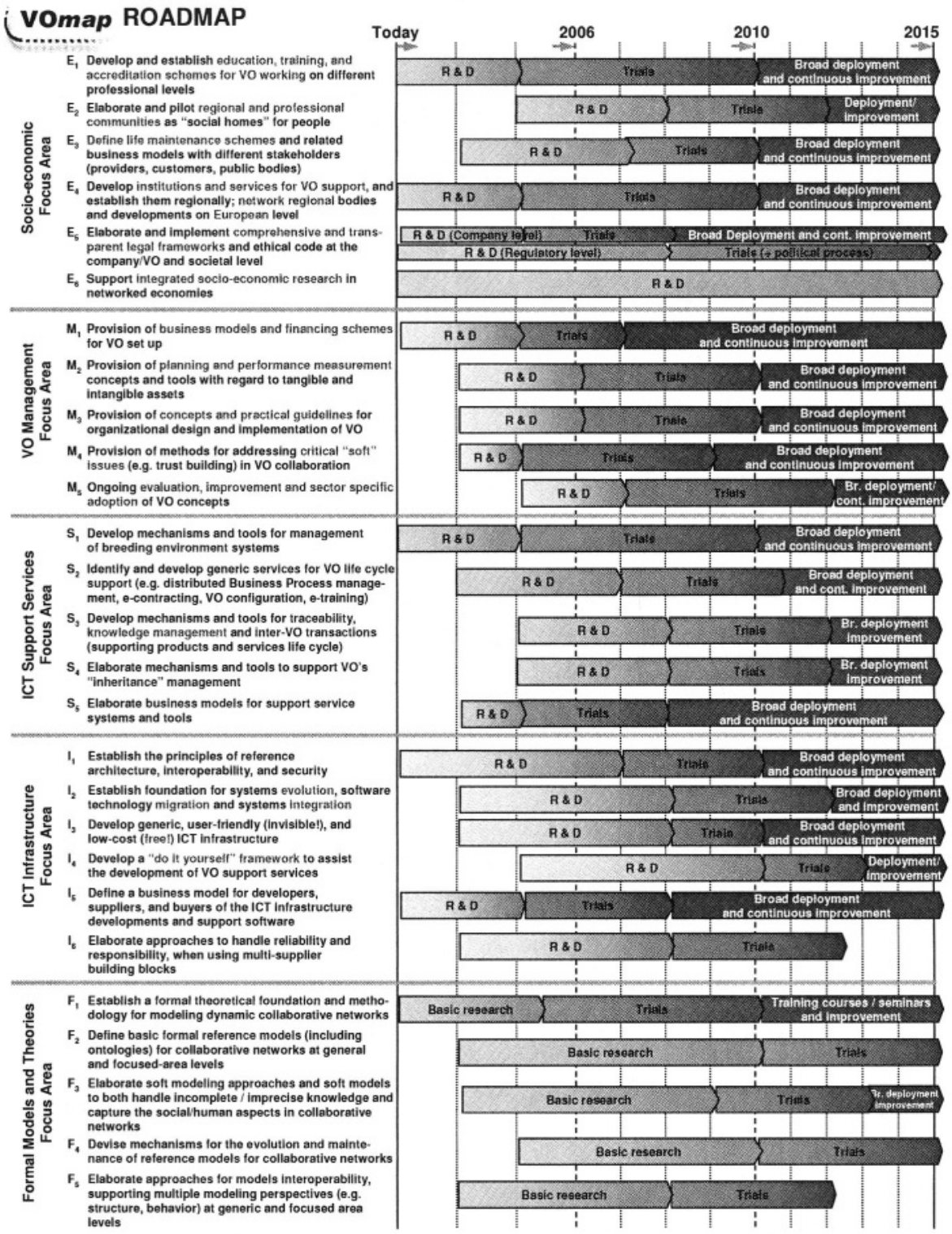

Figure 4 - VOmap roadmap for strategic research on advanced VOs

A substantial part of this roadmap is also taken as the starting basis for a new Integrated Project (ECOLEAD - European Collaborative Organizations LEADership Initiative) in the $6^{\text {th }}$ Framework Program of the European Commission (Fig. 5).

The IST THINKcreative project has also identified an ambitious research agenda for collaborative networks [3], involving a number of areas and disciplines as follows: 


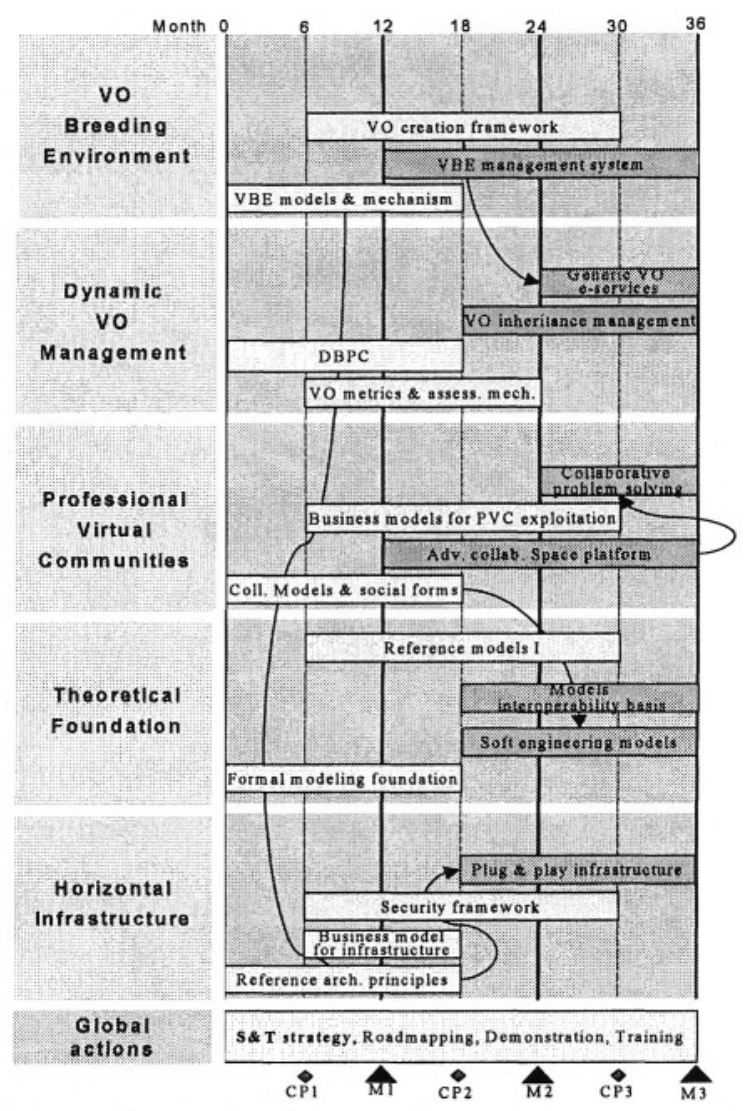

Figure 5 - ECOLEAD research plan

- ICT infrastructures. THINKcreative has identified the need for technologyindependent reference models for the support infrastructures of collaborative networked organizations, providing the framework for technical, organizational, and semantic interoperability. Multi-agent technology constitutes a promising contributor to the development of support infrastructures and services. Internet and web technologies, namely web services, represent a fast growing sector with large potential in inter-enterprise collaboration support but further developments in terms of supporting multi-party collaboration are necessary. A number of other emerging technologies e.g. grid, wireless communications, pervasive computing, location-aware and situation-aware environments for mobile users, are likely to provide important contributions, however public funded research should avoid approaches that are too-biased by existing technologies.

- Non-technologic areas. THINKcreative has identified a set of research challenges in the socio-economic, organizational, and ethical areas. Topics such as entrepreneurship for $\mathrm{CNs}$ in creative economy, mechanisms to support creativity and innovation, planning and controlling organization performance, understanding emerging behavior, new business ethics and morality, are among those suggested to be investigated. 
- Theoretical foundation. THINKcreative has identified the urgent need to establish a sound theoretical foundation for collaborative networks. This foundation can start with theories and models developed in other disciplines, e.g. multi-agent systems, complexity theories, self-organizing systems, graph theory, network analysis and game theory, formal engineering methods, formal theories, temporal and modal logic, semiotics, dynamic ontologies, metaphors, and others. As no single formal modeling tool / approach adequately covers all modeling perspectives / needs in collaborative networks, interoperability among different models seems necessary. Given the increasing importance of the human aspects in collaborative networks, a new foundation for modeling social aspects is also required.

Other roadmaps have also been proposed recently, addressing some of the related research challenges to collaborative networks. For instance, the COCONET roadmap [8] is focused on virtual communities and their cooperation environments, the IDEAS roadmap [9] addresses needs for supporting interoperability of ICT infrastructures, the Semantic Grid roadmap [10] focuses on e-Science and GRID infrastructure needs, and the Assembly-net roadmap [11] discusses research challenges in advanced collaborative manufacturing systems.

\section{EDUCATION AND PROFESSIONALISM}

"Community development" through education and professional associativism is essential to the widespread recognition of a discipline. Several activities that have taken place during last years have contributed to the establishment of a significant community of professionals involved in collaborative networks. Some examples:

- Education activities. Some universities already offer courses on virtual organizations / virtual enterprises [12]. For instance, the New University of Lisbon (Portugal) offers a 1-semester course on Virtual Enterprises to the $5^{\text {th }}$ year students of Electrical and Computer Engineering since 2002. Similarly the Federal University of Santa Catarina (Brazil) and the Costa Rican Institute of Technology started offering VE/VO courses to their students. Other universities are designing similar courses or including $\mathrm{CN}$-related modules in their existing curricula. An example is given by an American initiative [12] to launch a new course on virtual enterprises involving the collaboration of several different universities (forming a virtual institute). Other similar example courses are being developed in Europe at the Master program level.

- Scientific associations. Scientific associations play an important role as facilitators and promoters of collaboration among professionals involved in a specific discipline. Some initiatives in this area have been launched in recent years. For instance, at the IFIP (International Federation for Information Processing) level, a Working Group on Infrastructures for Virtual Enterprises and e-Business (COVE - CO-operation infrastructure for Virtual Enterprises and electronic business) was established under its Technical Committee 5 [www.uninova.pt/ cove]. Another example is the ESoCEnet (European Society of Concurrent Enterprising Network) established in Italy [www.esoce.net]. 
- Conferences. Professional and scientific conferences provide a forum to discuss current thoughts and experiences, as well as a channel to publish emerging ideas. The IFIP Working Conference series PRO-VE [www.pro-ve.org], the first yearly conference focused on Virtual Enterprises started in 1999, and since has established itself as the reference conference and most focused scientific event on collaborative networks, attracting a good number of professionals from academia and industry. Another related event, more focused on the Concurrent / Collaborative Engineering aspects is the ICE conference [www.iceconference.org].

- Journals. Scientific journals represent the most traditional channel to publish mature results in any scientific field. Currently, the lack of a scientific journal for collaborative networks represents a major difficulty for the $\mathrm{CN}$ community. The lack of a well-established journal in this area forces researchers to publish their results in diverse journals from other disciplines, what greatly reduces their potential impact. Nevertheless, some special issues on VE/VO have been already published by different journals such as Computers in Industry, IJ of Intelligent Manufacturing, IJ of Computer Integrated Manufacturing, etc. An attempt to launch an electronic journal on virtual organizations faced the typical difficulties of other electronic publications that do not seem able to survive [www.virtualorganization.net/]. A more recent initiative, the IJ of Networking and Virtual Organizations, offers a proper scope for publishing $\mathrm{CN}$ results, but it is still unclear whether it will become a major journal. Therefore, a focused and wellreputed journal focused on Collaborative Networks is still needed for this community.

These examples illustrate the trends in the $\mathrm{CN}$ community building process, which give a good basis for the sustainability of the new discipline. The establishment of $\mathrm{CN}$ as a recognized scientific discipline will likely have a boosting effect on these activities.

\section{CONCLUSIONS}

A growing number of collaborative-networked organization forms are emerging as a result of the advances in the information and communication technologies, the market and societal needs, and the progress achieved in a large number of international projects. The accumulated body of empiric knowledge and the size of the involved research community provide the important pre-conditions for the foundation of a new scientific discipline of collaborative networks. The organization of such discipline is likely to have a boosting effect in the development and consolidation of the area, both in terms of research, and practical implantation.

Furthermore, this process, leading to the establishment of a scientific discipline, is likely to bring a number of advantages to the progress of the area:

- In order to gain strength, when free from the assumptions of other specific disciplines that were contributing to the area, the associated body of knowledge will get more focused and organized.

- Researchers will dedicate their energy on many challenging issues raised by the new area instead of fighting their colleagues from other disciplines, either 
trying to claim the ownership of the area, or to prove the primacy of their former base discipline in tackling these challenges.

- Researchers will get / build new instruments to get their work recognized and respected in the established academia such as:

- A well delimited scope of their activity. Nowadays, due to its multidisciplinarity, research on collaborative network tends to not be well accepted by the "traditional" disciplines. For instance, some groups in the computer science area have not yet fully accepted this research area, because it involves social sciences, management, manufacturing, and industrial engineering. At the same time, for instance the management area has not fully accepted it because it has strong involvement with technology and the computer science area. For a scientific discipline to be recognized, it needs to have unique principles and practices, and a research community that generates its own literature and supports its education.

- Well-established communication and interaction channels. Conferences, journals, praxis, professional associations, etc. shall form the basis for sustaining the associated research community.

Collaborative networks are already recognized in the society as a very important instrument for survival of organizations in a period of turbulent socio-economic changes. Thus, seizing the opportunity to structure this area as a new scientific discipline is a major challenge for the associated research community.

Acknowledgements. This work got partial support from the European Commission (projects THINKcreative, VOmap, VOSTER, and ECOLEAD) and the authors thank the contribution from their partners in such projects.

\section{REFERENCES}

1. Liles, D.; Johnson, M.; Meade, L.; Underdown, D. - Enterprise Engineering: A discipline?, Society for Enterprise Engineering (SEE) Conference, Orlando, FL, 1995, http://www.webs.twsu.edu/enteng/ENTENGl.html

2. Kuhn, T. S. - The structure of scientific revolutions, Univ. of Chicago Press, 2nd edition, 1975.

3. Camarinha-Matos, L.M.; Afsarmanesh, H. (Ed.s) - Collaborative networked organizations - A research agenda for emerging business models, Kluwer Academic Publishers, March 2004.

4. Camarinha-Matos, L.M.; et al. - Emerging collaborative forms, in Collaborative Networked Organizations, Kluwer Academic Publishers, March 2004.

5. Barata, J.; Camarinha-Matos, L.M. - Coalitions of manufacturing components for shopfloor agility, in Int. Journal ofNetworking and Virtual Organizations, Vol. 2, $\mathrm{N}^{\circ}$ $1,2003$.

6. Camarinha-Matos, L.M.; Afsarmanesh, H. - A roadmap for strategic research on virtual organizations, in Processes and Foundations for Virtual Organizations, Kluwer Academic Publishers, Oct 2003.

7. Camarinha-Matos, L.M.; Afsarmanesh, H.; Loeh, H.; Sturm, F.; Ollus, M. - A strategic roadmap for advanced virtual organizations, in Collaborative Networked Organizations, Kluwer Academic Publishers, March 2004. 
8. Schaffers, H.; Ribak, A.; Tschammer, V. - COCONET: A roadmap for context-aware cooperation environments, in Processes and Foundations for Virtual Organizations, Kluwer Academic Publishers, Oct 2003.

9. Chen, D.; Doumeingts, G. - Basic Concepts and Approaches to develop interoperability of enterprise applications, in Processes and Foundations For Virtual Organisations, Kluwer Academic Publishers, Oct 2003.

10. Roure, D.; Jennings, N.; Shadbolt, N. - Research Agenda for the Semantic Grid: A future e-Science infrastructure, EPSRC/DTI Core e-Science Programme, 2001.

11. Onori, M.; Barata Oliveira, J.; Lastra, J.; Tichem, M. - European Precision Assembly - Roadmap 2010, Assembly-Net, ISBN 91-7283-637-7, Dec 03.

12. COVE Newsletter, No 6, Dec 2003, ISSN 1645-0582, www.uninova.pt/ cove/COVENews6.pdf. 